\title{
Multivitamin restriction increases adiposity and disrupts glucose homeostasis in mice
}

\author{
Nisserine Ben Amara $\cdot$ Julie Marcotorchino • \\ Franck Tourniaire · Julien Astier • Marie-Josèphe Amiot • \\ Patrice Darmon · Jean-François Landrier
}

Received: 27 January 2014/ Accepted: 14 May 2014/Published online: 25 May 2014

(C) Springer-Verlag Berlin Heidelberg 2014

\begin{abstract}
A strong association between obesity and low plasma concentrations of vitamins has been widely reported; however, the causality of this relationship is still not established. Our goal was to evaluate the impact of a multivitamin restriction diet (MRD) on body weight, adiposity and glucose homeostasis in mice. The mice were given a standard diet or a diet containing $50 \%$ of the recommended vitamin intake (MRD) for 12 weeks. At the end of the experiment, total body weight was $6 \%$ higher in MRD animals than in the control group, and the adiposity of the MRD animals more than doubled. The HOMA-IR index of the MRD animals was significantly increased. The
\end{abstract}

Nisserine Ben Amara and Julie Marcotorchino have contributed equally to this work.

Patrice Darmon and Jean-François Landrier have contributed equally to this work.

Electronic supplementary material The online version of this article (doi:10.1007/s12263-014-0410-x) contains supplementary material, which is available to authorized users.

N. B. Amara - J. Marcotorchino - F. Tourniaire - J. Astier .

M.-J. Amiot · P. Darmon - J.-F. Landrier

INRA, UMR 1260, 13385 Marseille, France

N. B. Amara - J. Marcotorchino - F. Tourniaire - J. Astier .

M.-J. Amiot · P. Darmon · J.-F. Landrier

INSERM, UMR 1062, Nutrition, Obésité et Risque

Thrombotique, 13385 Marseille, France

N. B. Amara - J. Marcotorchino - F. Tourniaire - J. Astier ·

M.-J. Amiot · P. Darmon ( $\square)$ · J.-F. Landrier $(\square)$

UMR 1260 INRA/1062 INSERM, Faculté de Médecine,

Aix-Marseille Université, 27 Bd Jean Moulin,

13385 Marseille Cedex 05, France

e-mail: Patrice.DARMON@ap-hm.fr

J.-F. Landrier

e-mail: jean-francois.landrier@univ-amu.fr adipose tissue of MRD animals had lower expression of mRNA encoding adiponectin and Pnpla2 (47 and $32 \%$, respectively) and $43 \%$ higher leptin mRNA levels. In the liver, the mRNA levels of Ppar $\alpha$ and Pgc1 $\alpha$ were reduced (29 and $69 \%$, respectively) in MRD mice. Finally, the level of $\beta$-hydroxybutyrate, a ketonic body reflecting fatty acid oxidation, was decreased by $45 \%$ in MRD mice. Our results suggest that MRD promotes adiposity, possibly by decreasing adipose tissue lipolysis and hepatic $\beta$-oxidation. These results could highlight a possible role of vitamin deficiency in the etiology of obesity and associated disorders.

Keywords Vitamins - Obesity · Adiposity - HOMA-IR . Healthy pattern

\section{Introduction}

Obesity is a worldwide health problem that affects more than $10 \%$ of the world's adult population. The World Health Organization (WHO) has identified the increased intake of energy-dense foods that are rich in fat, salt and sugars but poor in vitamins, minerals and other micronutrients, together with decreased physical activity, as major causes of obesity and overweight (WHO 2012).

Indeed, obesity is frequently associated with vitamin deficiency (Garcia et al. 2009). In particular, vitamin D together with B group vitamins has been reported to be deficient in obesity, particularly in morbidly obese individuals. One study highlighted the deficiency of vitamin D and B group vitamins in obesity (Kaidar-Person et al. 2008), whereas another study reported that levels of vitamin B6, vitamin C, 25-hydroxy-vitamin D and lipid-corrected vitamin $\mathrm{E}$ were significantly lower in obese 
individuals compared with a control population (Aasheim et al. 2008). However, the causality between low vitamin status and obesity remains particularly difficult to establish, especially in humans.

In animal models, several experiments have been performed on pregnant female rats to identify the possible impact of maternal vitamin supplementation or deficiency on offspring phenotype. These experiments suggest that the vitamin content of the diet influences adiposity and body fat content. In fact, multivitamin supplementation (tenfold increase) in rats during pregnancy results in increased food intake and obesity (Szeto et al. 2008, 2009). Interestingly, an increase of body fat content has also been observed in the offspring of female rats receiving a $50 \%$ restricted vitamin diet (Venu et al. 2004). Similarly, a folate and vitamin B12 deficiency in female-weaning rats have been shown to result in increased adiposity in offspring (Kumar et al. 2013).

However, the impact of multivitamin deficiency on the adiposity of adults has never been explored. In the present study, we evaluated adiposity and other parameters, such as glycemia and insulinemia, in mice fed a control diet or multivitamin-restricted diet (MRD) containing $50 \%$ of the required amounts of vitamins. Gene expression analysis was performed to evaluate whether the fat mass gain observed in MRD-fed mice could result, at least in part, from the reduction of adipose lipolysis and hepatic lipid oxidation.

\section{Materials and methods}

\section{Animal experiments}

The protocol was approved by the local ethics committee. Six-week-old male C57BL/6 J Rj mice were obtained from Janvier (Le Genest Saint Isle, France) and fed ad libitum with a control diet or a diet containing $50 \%$ of the recommended quantity of vitamins (Tables 1, 3), TD06416 and TD10959, respectively, from Harlan (Indianapolis, IN, USA), with full access to drinking water. The animals were maintained in a room at $22{ }^{\circ} \mathrm{C}$ on a 12 -hour light:12-hour dark cycle with a humidity level of $50 \%$. In both groups, minerals were supplied as recommended (Table 2 ). Mice (10 per group) were assigned to one of the two experimental groups depending on their diet, i.e., control or multivitamin restricted, for 10 weeks. Weight gain was measured every week, and energy intake was calculated per cage from the amount of food consumed by the animals and its caloric equivalence. At the end of treatment period, mice were fasted overnight and blood was collected by cardiac venipuncture under anesthesia. Animals were then killed by cervical dislocation. Immediately after dissection, epidydimal, peri-renal and
Table 1 Formula of diets

\begin{tabular}{lll}
\hline & $\begin{array}{l}\text { Control diet } \\
\text { TD06416 }(\mathrm{g} / \mathrm{kg})\end{array}$ & $\begin{array}{l}\text { Multivitamin-restricted } \\
\text { diet TD10959 }(\mathrm{g} / \mathrm{kg})\end{array}$ \\
\hline Casein & 210 & 210 \\
L-Cysteine & 3 & 3 \\
Corn starch & 280 & 287.5 \\
Maltodextrin & 50 & 50 \\
Lard & 20 & 20 \\
Soybean oil & 20 & 20 \\
Cellulose & 37.15 & 37.15 \\
Sucrose & 325 & 325 \\
Mineral mix, & 35 & 35 \\
$\quad$ AIN-93G-MX & & \\
Calcium phosphate, & 2 & 2 \\
$\quad$ dibasic & & 7.5 \\
Vitamin mix, & 15 & \\
$\quad$ AIN-93-VX & & 2.75 \\
Choline bitartrate & 2.75 & 3.728 \\
Estimated energy & 3.7 & \\
amount (Kcal/g) & & \\
\hline
\end{tabular}

${ }^{a}$ Precise composition of mineral mix given in Table 2

${ }^{b}$ Precise composition of vitamin mix given in Table 3

Table 2 Quantity of mineral elements contained in diets

\begin{tabular}{lll}
\hline & $\begin{array}{l}\text { Control diet } \\
\text { TD06416 }(\mathrm{mg} / \mathrm{kg})\end{array}$ & $\begin{array}{l}\text { Multivitamin-restricted } \\
\text { diet TD10959 }(\mathrm{mg} / \mathrm{kg})\end{array}$ \\
\hline Calcium & 5,000 & 5,000 \\
Phosphorus & 1,561 & 1,561 \\
Potassium & 3,600 & 3,600 \\
Sulfur & 300 & 300 \\
Sodium & 1,019 & 1,019 \\
Chloride & 1,571 & 1,571 \\
Magnesium & 507 & 507 \\
Iron & 35 & 35 \\
Zinc & 30 & 30 \\
Manganese & 10 & 10 \\
Copper & 6 & 6 \\
Iodine & 0.2 & 0.2 \\
Molybdenum & 0.15 & 0.15 \\
Selenium & 0.15 & 0.15 \\
Silicon & 5 & 5 \\
Chromium & 1 & 1 \\
Fluoride & 1 & 1 \\
Nickel & 0.5 & 0.5 \\
Boron & 0.5 & 0.5 \\
Lithium & 0.1 & 0.1 \\
Vanadium & 0.1 & 0.1 \\
\hline & &
\end{tabular}

inguinal adipose depots were weighed. Liver samples were also collected. Samples were snap-frozen in liquid nitrogen and stored at $-80{ }^{\circ} \mathrm{C}$ until use. 
Table 3 Quantity of vitamins contained in diets

\begin{tabular}{|c|c|c|}
\hline & $\begin{array}{l}\text { Control diet } \\
\text { TD.06416 (U/kg) }\end{array}$ & $\begin{array}{l}\text { Multivitamin-restricted diet } \\
\text { TD10959 (U/kg) }\end{array}$ \\
\hline $\begin{array}{l}\text { Nicotinic } \\
\text { acid }(\mathrm{mg})\end{array}$ & 45 & 22.5 \\
\hline $\begin{array}{l}\text { Pantothenate } \\
\text { (mg) }\end{array}$ & 22.5 & 11.25 \\
\hline $\begin{array}{l}\text { Pyridoxine } \\
(\mathrm{mg})\end{array}$ & 9 & 4.5 \\
\hline $\begin{array}{l}\text { Thiamin } \\
(\mathrm{mg})\end{array}$ & 7.5 & 3.75 \\
\hline $\begin{array}{l}\text { Riboflavin } \\
(\mathrm{mg})\end{array}$ & 9 & 4.5 \\
\hline $\begin{array}{l}\text { Folic acid } \\
\quad(\mathrm{mg})\end{array}$ & 3 & 1.5 \\
\hline $\begin{array}{l}\text { Vitamin } \mathrm{K} \\
(\mu \mathrm{g})\end{array}$ & 1,125 & 562.5 \\
\hline D-Biotin $(\mu \mathrm{g})$ & 300 & 150 \\
\hline $\begin{array}{l}\text { Vitamin } \\
\text { B-12 }(\mu \mathrm{g})\end{array}$ & 37.5 & 18.75 \\
\hline $\begin{array}{l}\text { Vitamin A } \\
\text { (IU) }\end{array}$ & 6,000 & 3,000 \\
\hline $\begin{array}{l}\text { Vitamin D3 } \\
\text { (IU) }\end{array}$ & 1,500 & 750 \\
\hline $\begin{array}{l}\text { Vitamin E } \\
\text { (IU) }\end{array}$ & 112.5 & 56.25 \\
\hline
\end{tabular}

RNA isolation and qPCR

Total RNA was extracted from the tissues (epidydimal adipose tissue and liver) using TRIzol reagent according to the manufacturer's instructions (Life Technologies, Saint Aubin, France). RNA purity was evaluated by measuring the absorbance at 260/280 and 260/230 nm ratios using spectrometry. Real-time quantitative PCR analyses were performed using the Mx3005P Real-Time PCR System (Stratagene, La Jolla, CA). For each condition, expression was quantified in duplicate, and 18S rRNA was used as an endogenous control in the comparative cycle threshold $\left(\mathrm{C}_{\mathrm{T}}\right)$ method. Data were expressed as a relative expression ratio as previously described (Landrier et al. 2008). The primers used in this study are listed in Supplemental Table 1 (Table S1).

\section{Analysis of plasma samples}

The glucose concentration in the plasma was evaluated using glucose RTU (bioMerieux, Craponne, France). The insulin concentration in the plasma was quantified using an ELISA kit (Mercodia, Uppsala, Sweden). The $\beta$-hydroxybutyrate concentration was measured using a colorimetric test according to the manufacturer's procedure (BEN srl, Milano, Italy). The plasma 25-hydroxy-vitamin D concentration was measured using an ELISA kit (Promokine,
Table 4 Plasma levels of vitamins

\begin{tabular}{lcc}
\hline & $\begin{array}{l}\text { Standard diet } \\
\text { mice }\end{array}$ & $\begin{array}{l}\text { Multivitamin-restricted } \\
\text { diet mice }\end{array}$ \\
\hline Retinol $(\mu \mathrm{mol} / \mathrm{l})$ & $0.85 \pm 0.3$ & $0.98 \pm 0.21$ \\
Vitamin E $(\mu \mathrm{mol} / \mathrm{l})$ & $3.11 \pm 0.77$ & $2.58 \pm 0.24$ \\
25-OH-VD $(\mathrm{nmol} / \mathrm{l})$ & $23 \pm 3.99$ & $22 \pm 3.79$ \\
\hline
\end{tabular}

Promocell, Heidelberg, Germany). Levels of vitamin E and retinol were quantified by HPLC as previously described (Landrier et al. 2008).

Statistical analysis

Data are expressed as the means \pm SEM. Significant differences were determined by unpaired Student's $t$ test using Statview software (SAS Institute, Cary, NC). $p<0.05$ was considered to be statistically significant.

\section{Results}

A multivitamin restriction diet (MRD) increased body weight and adiposity

The effect of a MRD containing $50 \%$ of the amount of required vitamins compared with a normal vitamin diet was evaluated in wild-type C57BL/6 J male mice. No differences in plasma levels of retinol, vitamin $\mathrm{E}$ or 25-hydroxyvitamin $\mathrm{D}$ were observed between the two groups of animals (Table 4). However, after 12 weeks of the regimen (Fig. 1a), we observed that MRD increased the body weight $(6 \%)$ of mice compared with mice receiving the normal vitamin diet (Fig. 1b). This increase of body weight was associated with an increase of fat mass in MRD-fed mice. The masses of all fat pads measured (epididymal, peri-renal and inguinal; Fig. 1c) in MRD mice were twofold higher than those in mice receiving the normal diet. The increase in fat pad mass was maintained after adjustment for body weight (Fig. 1d). Consequently, the calculated adiposity index (ratio sum of fat pads/total mass of mice) was also twofold higher in MRD mice than in mice receiving the normal diet (Fig. 1e). Note that food intake (Fig. 1f) and energy intake (Fig. 1g) were comparable between the two experimental groups, suggesting that the alteration of body weight and adiposity did not result from differences in food intake.

MRD modified AdipoQ and Lep expression in adipose tissue

Because alterations of adipose tissue mass are associated with numerous gene expression modifications, notably the 

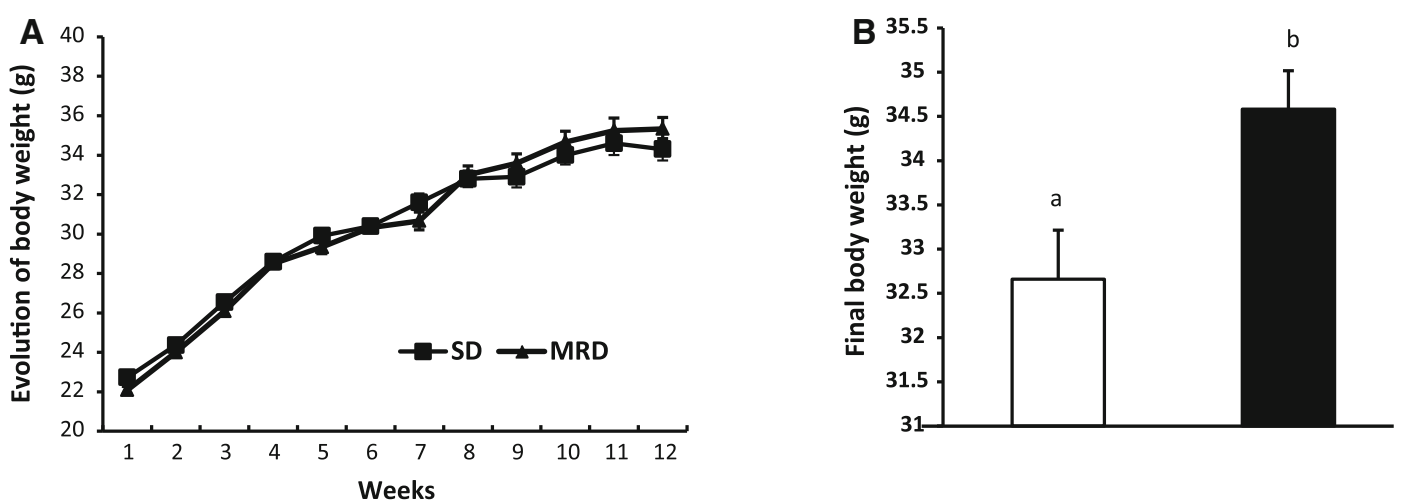
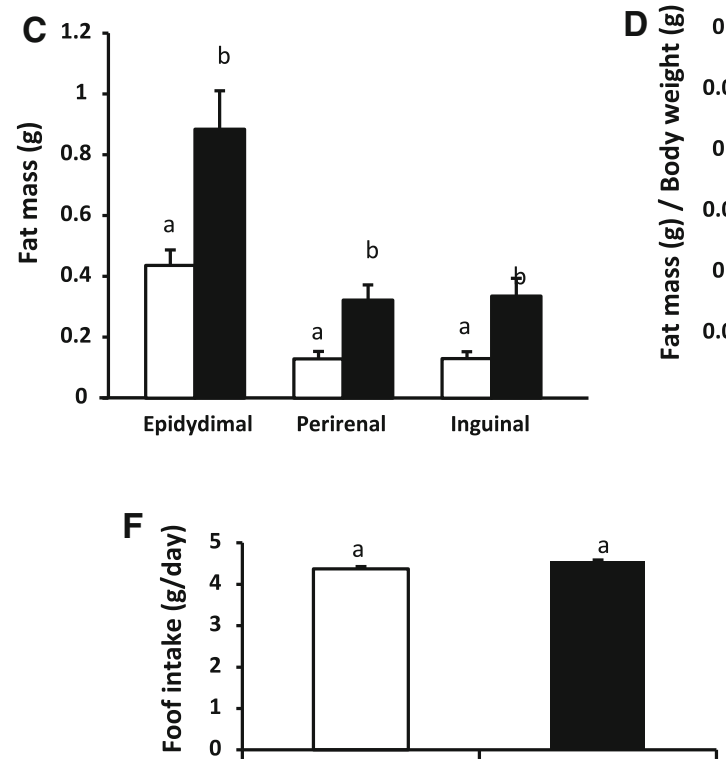

Fig. 1 Multivitamin restriction increases body weight and adiposity. a Body weight evolution was followed during the 12 weeks of treatment. b Before killing, animal weight was established. c At the time of killing, after 12 weeks of treatment, adipose tissues (epididymal, subcutaneous and peri-renal) were weighed for each animal $(n=10)$. $\mathbf{d}$ The fat mass is reported relative to the total body weight of the animal. e An adiposity index was calculated by calculating the
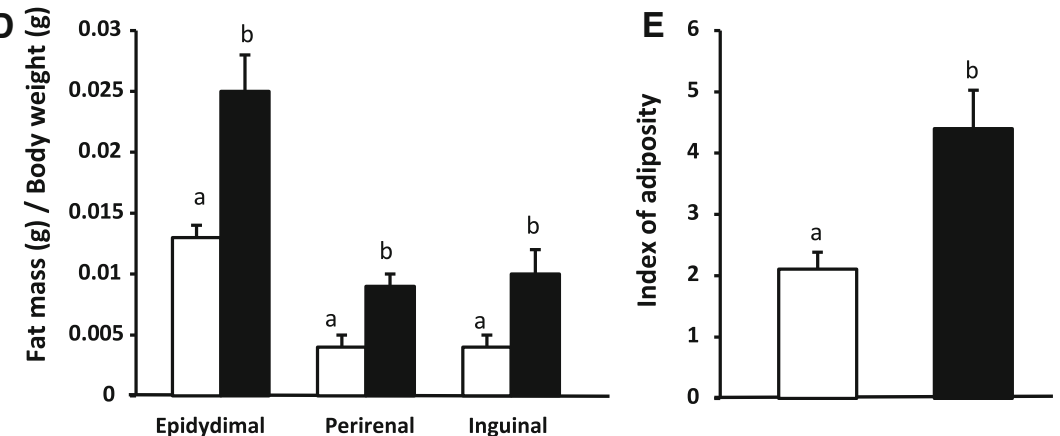

G $\underset{\frac{\pi}{0}}{\overparen{3}}$

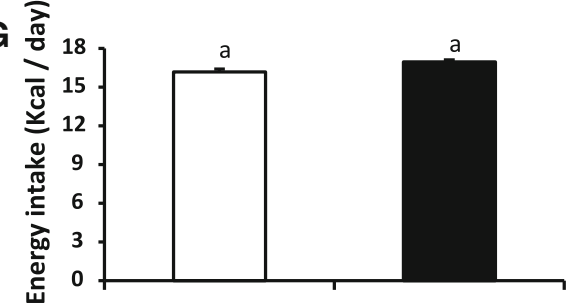

ratio between total fat mass and body weight for the animal. f Mean food intake was determined together with energy intake. $\mathrm{g}$ White bars correspond to mice submitted to the standard diet (SD), and black bars correspond to mice submitted to the multivitamin-restricted diet. Values are presented as the mean \pm SEM. Bars not sharing the same letter are significantly different, $p<0.05$

$(p=0.059)$ in the MRD group. However, the HOMA-IR index was significantly increased by $43 \%$ in MRD mice compared with mice receiving the normal diet (Fig. 3).

MRD altered levels of plasma markers of fatty acid oxidation, white adipose tissue and hepatic gene expression

Because the food intake of the mice was not affected by the MRD, we hypothesized that the energy metabolism was modified. Triglyceride lipolysis and fatty acid $\beta$-oxidation were explored through the expression of patatin-like phospholipase domain containing 2 (Pnpla2), the transcription factor Ppar $\alpha$ and a cofactor governing fatty acid 


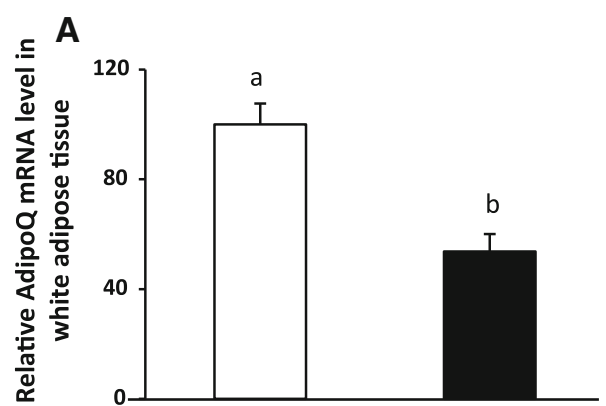

Fig. 2 Multivitamin restriction modifies AdipoQ and Lep expression in adipose tissue. $\mathbf{a}, \mathbf{b}$ Gene expression in white adipose tissue is expressed relative to $18 \mathrm{~S}$ ribosomal RNA levels in mice submitted to a standard diet (white bars) and multivitamin-restricted diet (black

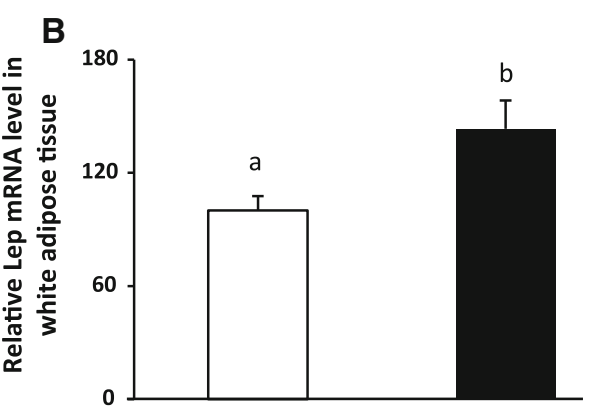

bars) for 12 weeks $(n=10)$. Values are presented as the mean \pm SEM. Bars not sharing the same letter are significantly different, $p<0.05$

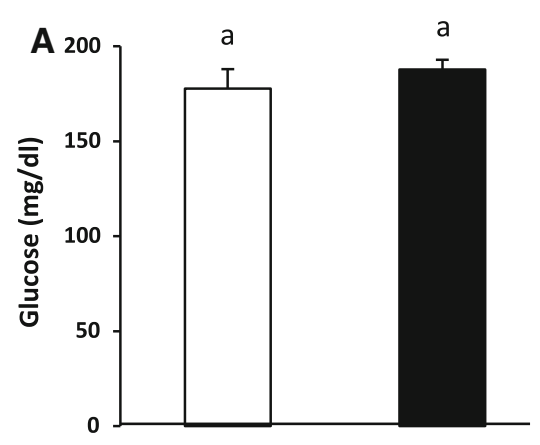

Fig. 3 Multivitamin restriction increases fasted insulinemia and HOMA-IR. a, b Insulin and glucose levels were measured after overnight fasting in the plasma of mice that received the standard diet (white bars) or multivitamin-restricted diet (black bars) for 12 weeks

oxidation in liver, Ppargc1 $\alpha$. The mRNA level of Pnpla2 was decreased by approximately $40 \%$ under MRD. In addition, the mRNA levels of Ppara and Ppargc1 $\alpha$ were strongly decreased in MRD, by approximately 29 and $69 \%$, respectively. To monitor fatty acid oxidation, the plasma concentration of the ketonic body $\beta$-hydroxybutyrate was assayed because in the fasted state, this ketonic body is produced by $\beta$-oxidation of fatty acids. A reduction of $40 \%$ in the $\beta$-hydroxybutyrate level was observed in MRD mice, suggesting lower oxidation of fatty acids in MRD mice compared to those receiving the normal diet (Fig. 4).

\section{Discussion}

The present study showed for the first time that a multivitamin restriction diet (MRD) administered to adult mice increases their body weight and fat mass and disrupts glucose homeostasis. Because the MRD did not alter food intake, our results highlight that lipolysis in adipose tissue

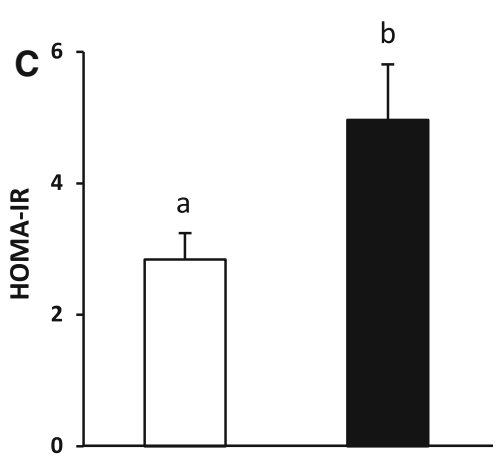

$(n=10)$. $\mathbf{c}$ The HOMA-IR index was calculated based on glycemia and insulinemia. Values are presented as the mean \pm SEM. Bars not sharing the same letter are significantly different, $p<0.05$

and hepatic fatty oxidation is impacted by multivitamin restriction, suggesting that modifications of lipid metabolism are associated with the observed phenotype, although we cannot exclude modifications of activity or thermogenesis, which were not measured in the present study.

We report here that a $50 \%$ restriction of vitamin supply is sufficient to modify the body weight and fat content of mice compared with a normal diet containing quantities of vitamins based on recommendations of the National Research Council Handbook (Subcommittee on Laboratory Animal Nutrition 1995). Nevertheless, it is necessary to consider that these recommendations are based on limited evidence, and it is currently considered that vitamins are present in large excess in rodent diets. However, our results agree with previous findings that vitamin inadequacy may influence several physiological processes, including immune response or energy homeostasis.

The goal of our study was to evaluate the impact of a global vitamin restriction, and not to evaluate the specific effect of each vitamin, because many studies have already reported the impact of isolated vitamin restriction/ 


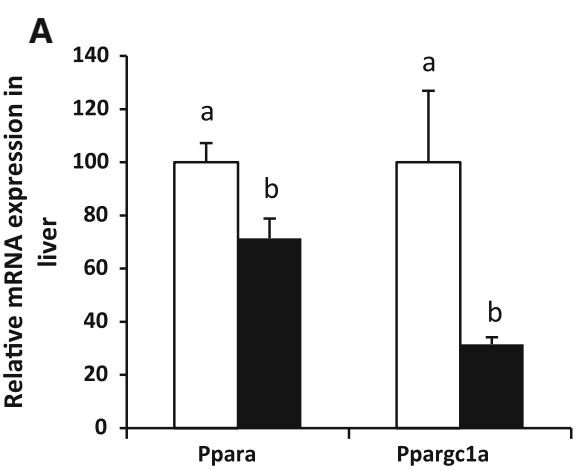

Fig. 4 Multivitamin restriction decreases gene expression in the liver and white adipose tissue and $\beta$-hydroxybutyrate levels in plasma. Gene expression relative to $18 \mathrm{~S}$ ribosomal RNA levels in the liver (a) and in white adipose tissue (b) of mice $(n=10)$ submitted to the standard diet (white bars) and multivitamin-restricted diet (black

supplementation on body weight management and adiposity. Indeed, vitamin A and its metabolites, i.e., retinoids (including all-trans retinoic acid and retinaldehyde) have been shown to reduce adiposity and body weight in several animal models (Bonet et al. 2000, 2003; Berry and Noy 2009; Ziouzenkova et al. 2007; Landrier et al. 2012; Tourniaire et al. 2009), and a low vitamin A status has been associated with an increase in white adipose tissue content (Bonet et al. 2000; Ribot et al. 2001). In addition, the regulation of RBP4 by vitamin A metabolites (Mercader et al. 2008) may also participate in the observed effect on insulin sensitivity. Low vitamin D intake could influence body weight and adiposity, and although the causality has not been proven, numerous epidemiological (cross-sectional and prospective) studies have shown a negative association between low levels of 25-hydroxy-vitamin D, the circulating form of vitamin D and obesity and associated pathologies (Garcia et al. 2009; Soares et al. 2011). Obese individuals have also been shown to have a lower level of the antioxidant vitamins $\mathrm{C}$ and $\mathrm{E}$ (Aasheim et al. 2008). Although the impact of vitamin E supplementation or deficiency on obesity in an animal model has never been reported, vitamin $\mathrm{C}$ supplementation has been shown to reduce the body weight of rats fed a cafeteria diet (Campion et al. 2006), suggesting that an adequate vitamin $C$ level may participate in body weight management. Vitamin $\mathrm{E}$ has been shown to impact adipocyte biology, leading to modulation of the secretion of adipokines (Landrier et al. 2009, 2012). Finally, the vitamin B group has also been negatively associated with overweight or obesity (Garcia et al. 2009; Aasheim et al. 2008). Within this vitamin group, few members are suspected to display a role in body weight management. However, thiamine (B1 vitamin) has been shown to prevent obesity and associated metabolic disorders in obese OLETF rats (Tanaka et al. 2010). Pantothenic acid (B5 vitamin) may also influence body weight bars) for 12 weeks. $\mathbf{c} \beta$-Hydroxybutyrate concentration in plasma of mice $(n=10)$ submitted to the standard diet (white bars) and multivitamin-restricted diet (black bars) for 12 weeks. Values are presented as the mean \pm SEM. Bars not sharing the same letter are significantly different, $p<0.05$

gain and lipid metabolism in obese mice (Naruta and Buko 2001), and nicotinic acid (B3 vitamin) increased adiponectin expression (Wanders et al. 2013), suggesting a specific effect of this vitamin on adipose tissue biology.

The present study, which highlights the impact of a global vitamin restriction on body weight and adiposity, paves the way for additional to determine a putative additive or synergistic effect of multivitamin restriction on body weight gain and increased adiposity compared with isolated vitamin restriction. However, it is necessary to consider that no modification of the plasma levels of the vitamins tested (retinol, vitamin E and 25-hydroxy-vitamin D) was observed. It should be noted that not all vitamins were quantified in the plasma; additionally, it would have been interesting to quantify vitamin levels in adipose tissue, which would have been even more relevant. This point represents a limitation of the present work, which will require further investigation.

Our study points to some molecular mechanisms related to lipid metabolism. First, Pnpla2 mRNA levels were reduced in the epidydimal fat pads of MRD mice. Pnpla2 was the first lipolysis enzyme discovered that provides substrates for hormone-sensitive lipase (Zimmermann et al. 2004, 1140), and its role in lipolysis has been notably demonstrated in vivo. Indeed, Pnpla $2^{-1-}$ mice present weight gain and increased adipose mass because of triglyceride accumulation (Haemmerle et al. 2006). Conversely, transgenic mice overexpressing Pnpla2 in adipose tissue display elevated lipolysis and increased fatty acid oxidation (Ahmadian et al. 2009). Together, these data suggest that decreased Pnpla2 expression could contribute to increased fat deposition, as observed in our study, through a reduction of lipolysis. In the liver, we observed that Ppargc1a and Ppara gene expression were significantly decreased in MRD mice. It is noteworthy that these genes encode key transcription factor regulators of hepatic FA 
oxidation because $\beta$-oxidation is impaired in both Ppargc $1 \mathrm{a}^{-/-}$and Ppara ${ }^{-/-}$mice (Wu et al. 1999; Lee et al. 1995). Thus, the reduced fatty acid flux consequent to lipolysis decrease may reduce hepatic fatty acid oxidation, as revealed by down-regulation of Ppara and Ppargcla. Additionally, we quantified $\beta$-hydroxybutyrate, a ketone body, in the plasma of mice. In the fasted state, ketone bodies arise from the $\beta$-oxidation of fatty acids that are primarily liberated from the lipolysis of the stored triglycerides in adipose tissue (Vice et al. 2005). Thus, the observed decrease of $\beta$-hydroxybutyrate observed in MRD mice is fully consistent with the hypothesis that restricted vitamin intake decreases adipose lipolysis and decreases $\beta$ oxidation in the liver. Nevertheless, the establishment of a causal relationship between these events and the identification of molecular mechanisms governing these gene modulations will require further investigation.

From a clinical point of view, these data strongly reinforce the putative role of vitamin inadequacy in the etiology of obesity, as previously suggested by others (Astrup and Bugel 2010). Our data are consistent with a crosssectional study showing that men consuming multivitamins and dietary supplements had lower body weight, fat mass and BMI (Major et al. 2008). Interestingly, a 10-year longitudinal study showed that long-term use of multivitamins is associated with lower levels of weight gain in overweight and obese subjects (Nachtigal et al. 2005). Finally, our results are also partly in agreement with a recent clinical trial that determined the effect of a multivitamin and mineral supplementation in obese Chinese women $(\mathrm{Li}$ et al. 2010). In that study, a lower body weight, lower fat mass and improvement of several parameters, including lipemia, were observed at the end of the supplementation. However, such supplementation involves both vitamins and minerals, whereas minerals were not studied in our experiments; thus, we cannot rule out the specific role of minerals in the reduction of body and fat mass.

To conclude, our study in mice suggests a role for vitamin insufficiency in obesity, although extensive further work is still required. Vitamin deficiency based on consumption of inexpensive but vitamin-poor foods may play a role in body weight and adiposity management (Kimmons et al. 2006). Our study contributes to the recommendation of a healthy diet composed of diverse food products with high vitamin density, such fruit and vegetables, whole-grain cereals and fish products.

Acknowledgments J.F.L. and P.D. conceived the experiments, and N.B.A., J.M., F.T., J.A. and J.F.L. performed experiments and analyzed data. J.F.L., M.J.A. and P.D. were involved in writing the paper and all authors had final approval of the submitted and published versions. This work was financially supported by INRA and AixMarseille University.
Conflict of interest N.B.A., J.M., F.T., J.A., M.J.A., P.D. and J.F.L. declare that they have no conflict of interest.

Ethical standard All institutional and national guidelines for the care and use of laboratory animals were followed.

\section{References}

Aasheim ET, Hofso D, Hjelmesaeth J, Birkeland KI, Bohmer T (2008) Vitamin status in morbidly obese patients: a crosssectional study. Am J Clin Nutr 87(2):362-369

Ahmadian M, Duncan RE, Varady KA, Frasson D, Hellerstein MK, Birkenfeld AL, Samuel VT, Shulman GI, Wang Y, Kang C, Sul HS (2009) Adipose overexpression of desnutrin promotes fatty acid use and attenuates diet-induced obesity. Diabetes 58(4):855-866

Astrup A, Bugel S (2010) Micronutrient deficiency in the aetiology of obesity. Int J Obes (Lond) 34(6):947-948

Berry DC, Noy N (2009) All-trans-retinoic acid represses obesity and insulin resistance by activating both peroxisome proliferationactivated receptor beta/delta and retinoic acid receptor. Mol Cell Biol 29(12):3286-3296

Bonet ML, Oliver J, Pico C, Felipe F, Ribot J, Cinti S, Palou A (2000) Opposite effects of feeding a vitamin A-deficient diet and retinoic acid treatment on brown adipose tissue uncoupling protein 1 (UCP1), UCP2 and leptin expression. J Endocrinol 166(3):511-517

Bonet ML, Ribot J, Felipe F, Palou A (2003) Vitamin A and the regulation of fat reserves. Cell Mol Life Sci 60(7):1311-1321

Campion J, Milagro FI, Fernandez D, Martinez JA (2006) Differential gene expression and adiposity reduction induced by ascorbic acid supplementation in a cafeteria model of obesity. J Physiol Biochem 62(2):71-80

Carbone F, La Rocca C, Matarese G (2012) Immunological functions of leptin and adiponectin. Biochimie 94(10):2082-2088

Garcia OP, Long KZ, Rosado JL (2009) Impact of micronutrient deficiencies on obesity. Nutr Rev 67(10):559-572

Haemmerle G, Lass A, Zimmermann R, Gorkiewicz G, Meyer C, Rozman J, Heldmaier G, Maier R, Theussl C, Eder S, Kratky D, Wagner EF, Klingenspor M, Hoefler G, Zechner R (2006) Defective lipolysis and altered energy metabolism in mice lacking adipose triglyceride lipase. Science 312(5774):734-737

Kaidar-Person O, Person B, Szomstein S, Rosenthal RJ (2008) Nutritional deficiencies in morbidly obese patients: a new form of malnutrition? Part A: vitamins. Obes Surg 18(7):870-876

Kimmons JE, Blanck HM, Tohill BC, Zhang J, Khan LK (2006) Associations between body mass index and the prevalence of low micronutrient levels among US adults. MedGenMed 8(4):59

Kumar KA, Lalitha A, Pavithra D, Padmavathi IJ, Ganeshan M, Rao KR, Venu L, Balakrishna N, Shanker NH, Reddy SU, Chandak GR, Sengupta S, Raghunath M (2013) Maternal dietary folate and/or vitamin B12 restrictions alter body composition (adiposity) and lipid metabolism in Wistar rat offspring. J Nutr Biochem 24(1):25-31

Landrier JF, Malezet-Desmoulins C, Reboul E, Marie Lorec A, Josephe Amiot M, Borel P (2008) Comparison of different vehicles to study the effect of tocopherols on gene expression in intestinal cells. Free Radic Res 42(5):523-530

Landrier JF, Gouranton E, El Yazidi C, Malezet C, Balaguer P, Borel P, Amiot MJ (2009) Adiponectin expression is induced by vitamin $\mathrm{E}$ via a peroxisome proliferator-activated receptor gamma-dependent mechanism. Endocrinology 150(12):5318-5325 
Landrier JF, Marcotorchino J, Tourniaire F (2012) Lipophilic micronutrients and adipose tissue biology. Nutrients 4(11):1622-1649

Lee SS, Pineau T, Drago J, Lee EJ, Owens JW, Kroetz DL, Fernandez-Salguero PM, Westphal H, Gonzalez FJ (1995) Targeted disruption of the alpha isoform of the peroxisome proliferator-activated receptor gene in mice results in abolishment of the pleiotropic effects of peroxisome proliferators. Mol Cell Biol 15(6):3012-3022

Li Y, Wang C, Zhu K, Feng RN, Sun CH (2010) Effects of multivitamin and mineral supplementation on adiposity, energy expenditure and lipid profiles in obese Chinese women. Int $\mathbf{J}$ Obes (Lond) 34(6):1070-1077

Major GC, Doucet E, Jacqmain M, St-Onge M, Bouchard C, Tremblay A (2008) Multivitamin and dietary supplements, body weight and appetite: results from a cross-sectional and a randomised double-blind placebo-controlled study. Br J Nutr 99(5):1157-1167

Mercader J, Granados N, Bonet ML, Palou A (2008) All-trans retinoic acid decreases murine adipose retinol binding protein 4 production. Cell Physiol Biochem 22(1-4):363-372

Nachtigal MC, Patterson RE, Stratton KL, Adams LA, Shattuck AL, White E (2005) Dietary supplements and weight control in a middle-age population. J Altern Complement Med 11(5):909-915

Naruta E, Buko V (2001) Hypolipidemic effect of pantothenic acid derivatives in mice with hypothalamic obesity induced by aurothioglucose. Exp Toxicol Pathol 53(5):393-398

Ribot J, Felipe F, Bonet ML, Palou A (2001) Changes of adiposity in response to vitamin A status correlate with changes of PPAR gamma 2 expression. Obes Res 9(8):500-509

Soares MJ, Chan She Ping-Delfos W, Ghanbari MH (2011) Calcium and vitamin D for obesity: a review of randomized controlled trials. Eur J Clin Nutr 65(9):994-1004

Subcommittee on Laboratory Animal Nutrition CoAN, Board on Agriculture, National Research Council (1995) Nutrient Requirements of Laboratory Animals. Washington, DC

Szeto IM, Aziz A, Das PJ, Taha AY, Okubo N, Reza-Lopez S, Giacca A, Anderson GH (2008) High multivitamin intake by Wistar rats during pregnancy results in increased food intake and components of the metabolic syndrome in male offspring. Am J Physiol Regul Integr Comp Physiol 295(2):R575-R582

Szeto IM, Das PJ, Aziz A, Anderson GH (2009) Multivitamin supplementation of Wistar rats during pregnancy accelerates the development of obesity in offspring fed an obesogenic diet. Int J Obes (Lond) 33(3):364-372

Tanaka T, Kono T, Terasaki F, Yasui K, Soyama A, Otsuka K, Fujita S, Yamane K, Manabe M, Usui K, Kohda Y (2010) Thiamine prevents obesity and obesity-associated metabolic disorders in OLETF rats. J Nutr Sci Vitaminol (Tokyo) 56(6):335-346

Tourniaire F, Gouranton E, von Lintig J, Keijer J, Luisa Bonet M, Amengual J, Lietz G, Landrier JF (2009) beta-Carotene conversion products and their effects on adipose tissue. Genes Nutr 4(3):179-187

Venu L, Harishankar N, Prasanna Krishna T, Raghunath M (2004) Maternal dietary vitamin restriction increases body fat content but not insulin resistance in WNIN rat offspring up to 6 months of age. Diabetologia 47(9):1493-1501

Vice E, Privette JD, Hickner RC, Barakat HA (2005) Ketone body metabolism in lean and obese women. Metabolism 54(11):1542-1545

Wanders D, Graff EC, White BD, Judd RL (2013) Niacin increases adiponectin and decreases adipose tissue inflammation in high fat diet-fed mice. PLoS One 8(8):e71285

WHO (2012) Obesity and overweight. WHO mediacenter

Wu Z, Puigserver P, Andersson U, Zhang C, Adelmant G, Mootha V, Troy A, Cinti S, Lowell B, Scarpulla RC, Spiegelman BM (1999) Mechanisms controlling mitochondrial biogenesis and respiration through the thermogenic coactivator PGC-1. Cell 98(1):115-124

Zimmermann R, Strauss JG, Haemmerle G, Schoiswohl G, BirnerGruenberger R, Riederer M, Lass A, Neuberger G, Eisenhaber F, Hermetter A, Zechner R (2004) Fat mobilization in adipose tissue is promoted by adipose triglyceride lipase. Science 306(5700):1383-1386

Ziouzenkova O, Orasanu G, Sharlach M, Akiyama TE, Berger JP, Viereck J, Hamilton JA, Tang G, Dolnikowski GG, Vogel S, Duester G, Plutzky J (2007) Retinaldehyde represses adipogenesis and diet-induced obesity. Nat Med 13(6):695-702 